\title{
Effect of an ionic liquid on the flexural and fracture mechanical properties of EP/MWCNT nanocomposites
}

\author{
Gábor SZEBÉNYI ${ }^{1, a^{*}}$, Levente Ferenc TÓTH ${ }^{1,2}$ b and József KARGER- \\ KOCSIS $^{1, C}$
}

\author{
${ }^{1}$ Budapest University of Technology and Economics, Faculty of Mechanical Engineering, \\ Department of Polymer Engineering, $\mathrm{H}-1111$ Budapest, Müegyetem rkp. 3, Hungary \\ ${ }^{2}$ Laboratory Soete, Faculty of Engineering and Architecture, Ghent University, B-9052 Zwijnaarde, \\ Technologiepark 903, Belgium \\ aszebenyi@pt.bme.hu, ${ }^{b}$ tothl@pt.bme.hu, ${ }^{c}$ karger@pt.bme
}

Keywords: carbon nanotubes, polymer composite, ionic liquid, interfacial adhesion

\begin{abstract}
The improvement of interfacial adhesion between multiwalled carbon nanotubes (MWCNTs) and epoxy resin (EP) was investigated in nanocomposites with the addition of an ionic liquid (IL, 1-Ethyl-3-methyl imidazolium tetrafluoroborate - EMIM $\mathrm{BF}_{4}$ ) as interfacial adhesion promoter. MWCNT (0, 0.3 and 0.5 weight $\%)$ was dispersed in EP through diluting an MWCNTrich masterbatch prepared in presence and absence of IL. Three point bending and compact tension (CT) fracture mechanical tests were performed on specimens with different MWCNT contents with and without IL surfactant. IL addition resulted in easier dispersion of MWCNT in the EP masterbatch. With the addition of the IL the three point bending strength, the bending modulus of elasticity and the critical force required for crack propagation have increased significantly at the optimal, 0.3 weight\% MWCNT content. Scanning electron microscopic (SEM) investigation of the fracture surfaces of the CT specimens revealed that incorporation of MWCNTs and its IL-assisted dispersion produced rougher surfaces suggesting higher fracture toughness than the reference EP.
\end{abstract}

\section{Introduction}

The discovery and development of high-strength and large surface-area nanoparticles (carbon nanotubes (CNTs), graphene, and nanoclays) holds numerous possible applications in the field of polymer matrix composites. While on the positive side these nanoparticles can provide mechanical reinforcement [1-3], improved thermal properties [4,5], improved electrical conductivity [6,7] and other interesting properties [8-10] for the polymeric matrices reinforced by them, they pose also some problems which have to be solved not only in laboratory scale but also at the industrial level.

One of the greatest advantages of nanoparticles is their orders of magnitude higher specific surface area compared to conventional micro-sized reinforcements and fillers. Through this interface they can adhere to the matrix, but also to each other, which can lead to the formation of agglomerates held together by secondary intermolecular forces and the mechanical entanglement of the curved nanoparticles. To create a composite with sufficient mechanical properties and fracture resistance these agglomerates have to be decomposed by a suitable mixing technology. While high energy ultrasonic (US) stirring proved to be effective at laboratory scale [11,12], most upscalable mixing technologies are based on high shear mechanical mixing methods like closed compartment high shear mixers $[13,14]$ and three roll mills $[15,16]$. The previously developed masterbatch mixing technology [17], used in this research, proved to be effective for the milling of the agglomerates, and for the efficient dispersion of the nanoparticles in both high and low viscosity thermoset resins.

The other problem with nanoparticles, like carbon nanotubes used in this research, is their weak interfacial adhesion to the thermoset matrix materials, which hinders the utilization of their superb strength. For the improvement of their interfacial adhesion various different approaches are reported 
in the literature: functionalization [18,19], covalent attachment of side-groups on the nanoparticle surface, plasma treatment [20], irradiation techniques [21-22], and the use of surfactants [23]. While functionalization can only be performed mostly at laboratory scale at the nanoparticles' manufacturer, plasma and irradiation techniques require access to expensive equipment, surfactants can also be used on site at the composite manufacturers. One group of promising candidate surfactants are ionic liquids showing good adhesion properties to both nanoparticles and polymeric matrices.

In our research we prepared multiwalled carbon nanotube (MWCNT) reinforced epoxy (EP) matrix composites with different MWCNT contents and added ionic liquids to test their effect on the interfacial properties of the prepared nanocomposites. Three point bending and compact tension fracture mechanical tests were performed and the fracture surfaces were investigated by scanning electron microscopy (SEM).

\section{Experimental}

Materials. ER 1010 DGEBA (Bisphenol A diglycidyl ether) epoxy resin was used (Ipox Chemicals Kft., Hungary) with MR 3124 curing agent (Ipox Chemicals Kft., Hungary) as matrix. The recommended mixing weight ratio was 100:35.

Baytubes ${ }^{\circledR}$ C 150 HP (Bayer, Germany), multiwalled carbon nanotubes (Fig. 1) were used as nanosized reinforcement. The nanotubes were produced by catalytic CVD method, which resulted loose aggregates, no functionalization has been used. The nanotubes were 13-16 nm in outer mean diameter, above $1 \mu \mathrm{m}$ in length, above $99 \%$ carbon purity content and free of amorphous carbon.

Basionics ${ }^{\circledR}$ EE 03 (1-Ethyl-3-methyl imidazolium tetrafluoroborate - EMIM BF 4 , BASF, Germany) ionic liquid was used as interfacial adhesion promoter.
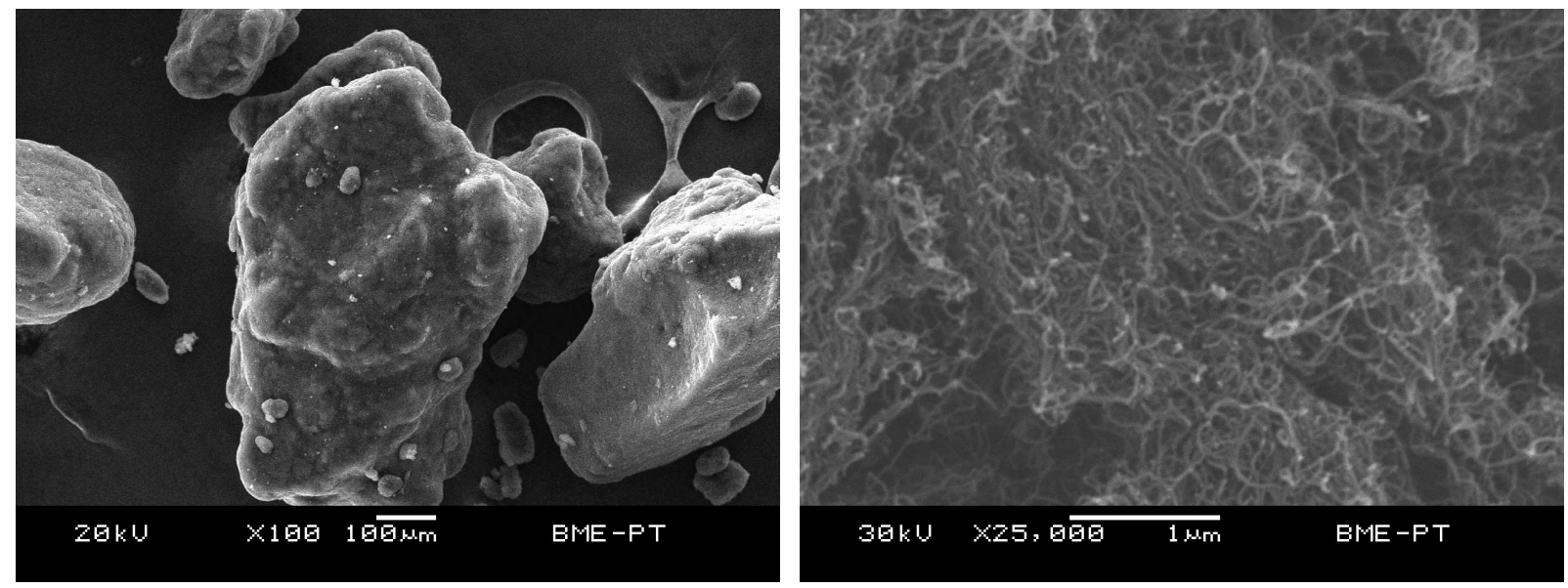

Fig. 1 SEM micrographs of the MWCNTs used

Mixing. A previously developed 3-step masterbatch technique based on three roll milling was used for the dispersion of the MWCNTs in the matrix. In the first step a 4 weight\% nanotube filled EP masterbatch has been premixed for 4 hours using an overhead stirrer. The so prepared mixture contained large, visible aggregates but its viscosity increased to the level where three roll milling became available. In the second step the masterbatch has been mixed on a three roll mill, 4 passthroughs have been carried out to reach the lowest achievable particle size. In the third step the almost solid masterbatch has been thinned with neat resin to the desired 0.3 and 0.5 weight $\%$ filler contents. The ionic liquid has been also mixed to the resin at this step in 0.6 weight $\%$ proportion.

Composite Preparation. The specimens were prepared by casting using silicone moulds representing the final contours of the standard test specimens. After curing for 48 hours at room temperature the specimens were removed from the mould and have been cured at $60^{\circ} \mathrm{C}$ for 4 hours on glass plates in a Heraeus UT 20 drying oven. In case of the CT specimens the notch has been 
machined in the center of the specimen using a Mutronic Diadisc diamond disc cutter and the sharp crack edge has been prepared using a razor blade.

Characterization. The effect of the IL addition has been characterized by three point bending and compact tension tests.

The three point bending tests have been performed using a Zwick Z020 universal, computer controlled testing machine, according to EN ISO 178. The support span was $64 \mathrm{~mm}$ and the test speed was $5 \mathrm{~mm} / \mathrm{min}$. The tests have been performed at room temperature.

The CT tests have been performed using a Zwick Z250 universal, computer controlled testing machine equipped with a $20 \mathrm{kN}$ load cell according to EN ISO 7539-6. A scale has been painted on the fracture surface to make crack propagation tracking easier and the crack was tracked using a high definition digital camera. The tests have been performed at $2 \mathrm{~mm} / \mathrm{min}$ crosshead speed at room temperature.

The fracture surfaces of the specimens have been examined using a JEOL JSM-6380LA SEM. The sample surfaces were gold spur coated using a JEOL FC 1200 device.

Results and Discussion. The beneficial effect on the dispersability of CNTs has been already witnessed during the thinning of the masterbatch. The IL containing samples could be more rapidly mixed.

According to the results of the three point bending tests the MWCNT addition has improved both the bending strength and the bending modulus of the EP significantly (Fig 2., Fig 3.).

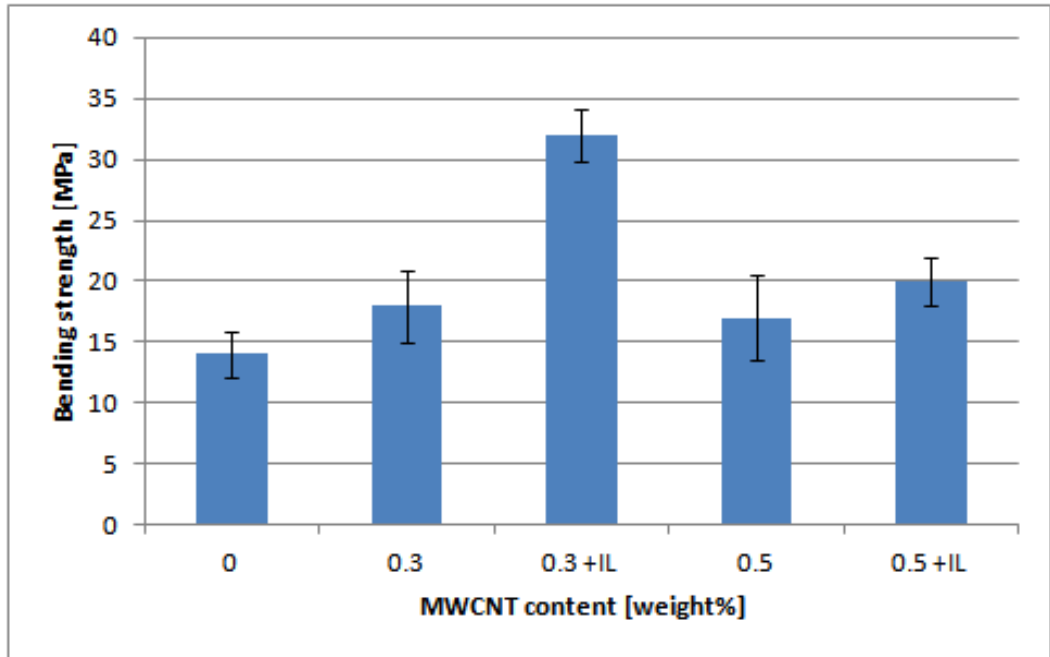

Fig. 2 Three point bending strength of the EP/MWCNT composites with 0.6 weight $\%$ and without $\mathrm{IL}$

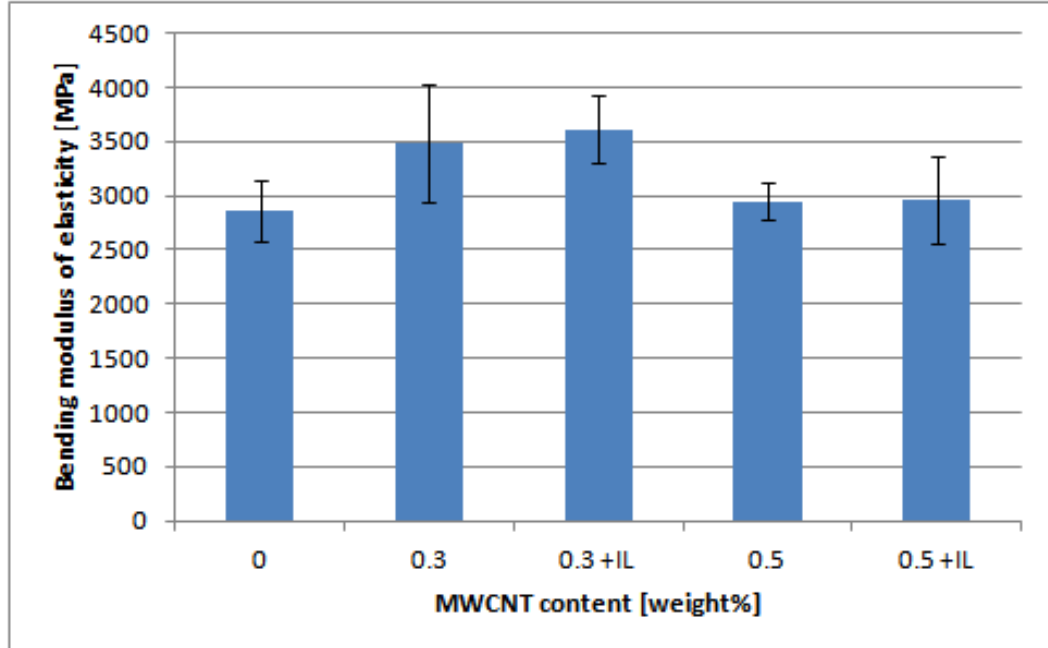

Fig. 3 Bending modulus of elasticity of the EP/MWCNT composites with 0.6 weight\% and without 
Comparing the only MWCNT containing composites results to the neat EP the reinforcing effect of MWCNTs becomes obvious. Both the strength and the modulus values increased significantly. With the addition of the IL to the system no further improvement can be seen in case of bending modulus. This is in line with the theory, that also particles with weak interfacial adhesion can improve the modulus of elasticity. In case of bending strength, where the interfacial adhesion has a much more dominant effect, the IL introduction yielded a prominent improvement.

The results of the CT tests are presented in Fig 4. The critical crack propagating force value was evaluated from force - crack opening displacement curves at the first crack jump.

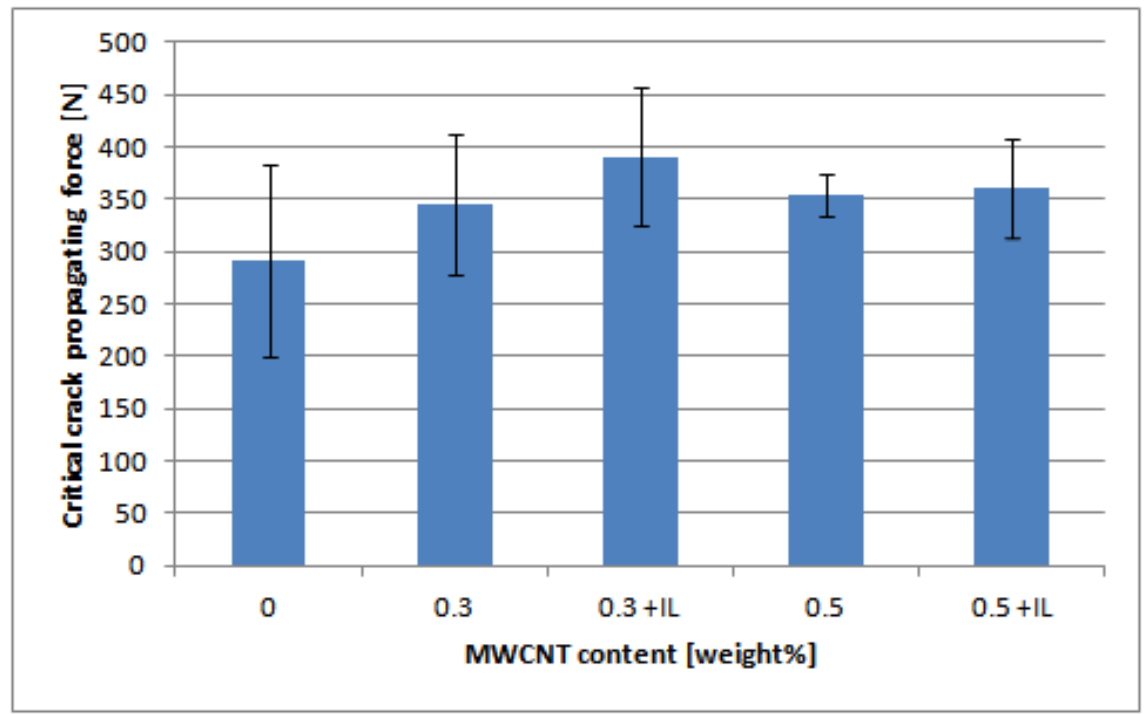

Fig. 4 Critical crack propagating force of the composites and the reference

According to the fracture mechanical test results the interfacial adhesion improvement between MWCNT and EP can be also observed, especially at the 0.3 weight $\%$ IL content. With the addition of the MWCNTs basically the stiffness of the EP was improved and the crack tip was blunted. With the addition of IL the adhesion improved between the matrix and the MWCNTs, and thus higher force was necessary to debond them and to initiate the crack propagation.

The SEM micrographs taken of the fracture surfaces of the neat epoxy, 0.3 weight\% MWCNT reinforced EP and the 0.3 weight $\%$ MWCNT reinforced EP with added IL are presented in Fig 5.
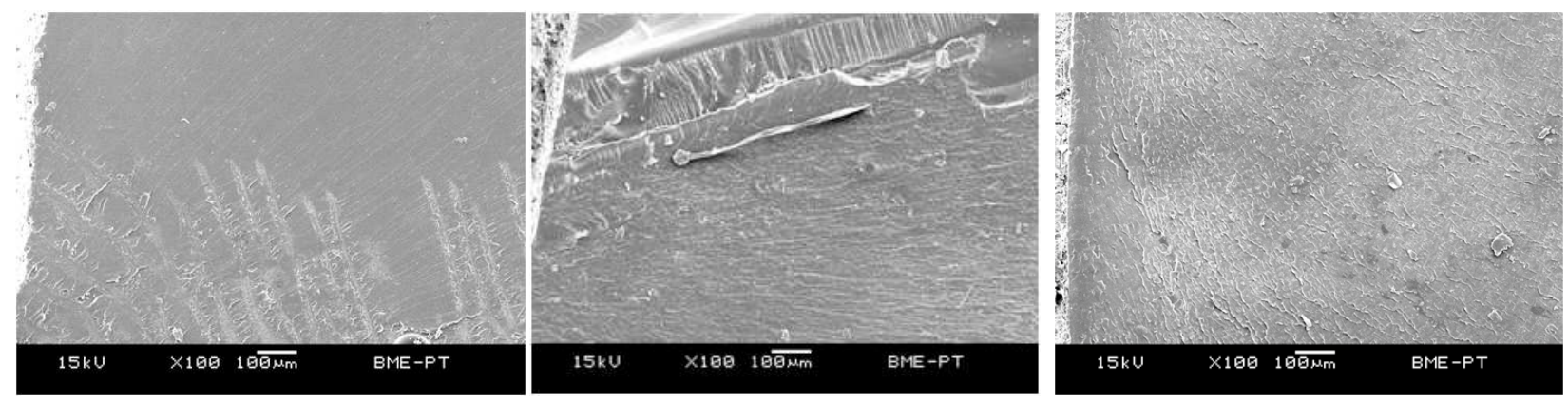

Fig. 5 SEM micrographs of the fracture surfaces of the CT specimens (epoxy - left side, epoxy + 0.3 weight\% MWCNTs - center, epoxy + 0.3 weight $\%$ MWCNTs - right)

The comparison of the SEM micrographs of the fracture surfaces at low magnifications supports our assumption. While the fracture surface of neat epoxy shows a mainly brittle fracture, the toughening effect of MWCNTs can be observed in the micrographs of the MWCNT reinforced samples. In case of the MWCNT and IL containing sample the fracture surface is finely textured, which suggests that higher energy was necessary for the crack propagation compared to the corresponding reference. 


\section{Summary}

Results of flexural and fracture mechanical investigations, along with fractographic inspection of the broken EP/MWCNT specimens, indicated that the addition of ionic liquid (IL) may strongly improve the mechanical and fracture mechanical characteristics. Both investigated adhesion dominated properties (three point bending strength, critical crack propagation force) increased significantly with the addition of the IL to the EP/MWCNT nanocomposites. The SEM micrographs showed that the fracture surface became rougher, suggesting higher fracture toughness according to the range: $\mathrm{EP}<\mathrm{EP} / \mathrm{MWCNT}<\mathrm{EP} / \mathrm{MWCNT/IL}$.

\section{Acknowledgements}

This work is connected to the scientific program of the 'Development of quality-oriented and harmonized $\mathrm{R}+\mathrm{D}+\mathrm{I}$ strategy and functional model at BME' project. This project was also supported by the New Széchenyi Plan (Project ID:TÁMOP-4.2.1/B-09/1/KMR-2010-0002). This paper was supported by National Research, Development and Innovation Office - NKFIH, OTKA K 116070. G. Szebényi acknowledges the financial support received through János Bolyai Scholarship of the Hungarian Academy of Sciences.

\section{References}

[1] F. H. Gojny, M. H. G. Wichmann, B. Fiedler, K. Schulte, Influence of different carbon nanotubes on the mechanical properties of epoxy matrix composites - A comparative study, Compos. Sci. Technol. 65 (2005), 2300-2313.

[2] S. Ganguli, M. Bhuyan, L. Allie, H. Aglan, Effect of multi-walled carbon nanotube reinforcement on the fracture behavior of a tetrafunctional epoxy, J. Mater. Sci. 40 (2005), 3593 3595 .

[3] A. T. Seyhan, F. H. Gojny, M. Tanoglu, K. Schulte, Critical aspects related to processing of carbon nanotube/unsaturated thermoset polyester nanocomposites, Eur. Polym. J. 43 (2007), 374379.

[4] J. Gu, X. Yang, Z. Lv, N. Li, C. Liang, Q. Zhang, Int. J. Heat Mass 92 (2016), 15-22.

[5] N. Ramdani, M. Derradji, . Feng, Z. Tong, J. Wang, E. Mokhnache, W. Liu, Preparation and characterization of thermally-conductive silane-treated silicon nitride filled polybenzoxazine nanocomposites, Mater. Lett. 155 (2015), 34-37.

[6] S. D. A. S. Ramoa, G. M. O. Barra, C. Merlini, S. Livi, B. G. Soares, A. Pegoretti, Novel electrically conductive polyurethane/montmorillonite-polypyrrole nanocomposites, Express Polym. Lett. 9 (2015), 945-958.

[7] X. Cheng, V. Kumar, T. Yokozeki, T. Goto, T. Takahashi, J. Koyanagi, L. Wu, R. Wang, Highly conductive graphene oxide/polyaniline hybrid polymer nanocomposites with simultaneously improved mechanical properties, Compos. Part A-Appl. S. 82 (2016), 100-107.

[8] K.A. Alnefaie, S.M. Aldousari, U.A. Khashaba, New development of self-damping MWCNT composites, Compos. Part A-Appl. S. 52 (2013), 1-11.

[9] R.K. Patel, B. Bhattacharya, S. Basu, Effect of interphase properties on the damping response of polymer nano-composites, Mech. Res. Commun. 35 (2008), 115-125.

[10] H. Liu, P. Bandyopadhyay, N. H. Kim, B. Moon, J. H. Lee, Surface modified graphene oxide/poly(vinyl alcohol) composite for enhanced hydrogen gas barrier film, Polym. Test. 50 (2016), 49-56. 
[11] W. Chen, H. Lu, S. R. Nutt, The influence of functionalized MWCNT reinforcement on the thermomechanical properties and morphology of epoxy nanocomposites, Compos. Sci. Technol. 68 (2008), 2535-2542.

[12] Y. S. Song, J. R. Youn, Influence of dispersion states of carbon nanotubes on physical properties of epoxy nanocomposites. Carbon 43 (2005), 1378-1385.

[13] M. Moniruzzaman, F. Du, N. Romero, K. I. Winey, Increased flexural modulus and strength in SWNT/epoxy composites by a new fabrication method, Polymer 47 (2006), 293-298.

[14]H. Chen, O. Jacobs, W. Wu, G. Rüdiger, B. Schaedel, Effect of dispersion method on tribological properties of carbon nanotube reinforced epoxy resin composites, Polym. Test. 26 (2007), 351-360.

[15] G. Szebényi, G. Romhány, Preparation of MWCNT reinforced epoxy nanocomposite and examination of its mechanical properties, Plast. Rubber Compos. 37 (2008), 214-218.

[16] A. Tuğrul Seyhan, M. Tanoğlu, K. Schulte, Tensile mechanical behavior and fracture toughness of MWCNT and DWCNT modified vinyl-ester/polyester hybrid nanocomposites produced by 3-roll milling, Mat. Sci. Eng.: A 523 (2009), 85-92.

[17]G. Szebényi, G. Romhány, The effect of different dispersion methods on the mechanical properties of MWCNT/carbon fiber/epoxy hibrid composites, in: 4th China-Europe Symposium on Processing and and Properties of Reinforced Polymers (2012), P-044.

[18] A. May-Pat, F. Aviles, P. Toro, M. Yazdani-Pedram, J. V. Cauich-Rodriguez, Mechanical properties of PET composites using multi-walled carbon nanotubes functionalized by inorganic and itaconic acids, Express Polym. Lett. 6 (2012), 96-106.

[19] Y. Luo, Y. Zhao, J. Cai, Y. Duan, S. Du, Effect of amino-functionalization on the interfacial adhesion of multi-walled carbon nanotubes/epoxy nanocomposites, Mater. Design 33 (2012), 405412.

[20] J. Li, Z. Wu, C. Huang, H. Liu, R. Huang, L. Li, Mechanical properties of cyanate ester/epoxy nanocomposites modified with plasma functionalized MWCNTs, Compos. Sci. Technol. 90 (2014), 166-173.

[21] G. Szebényi, G. Romhány, The effect of electron irradiation on the mechanical properties of MWCNT/carbon fiber reinforced hybrid nanocomposites, Mater. Sci. Forum. 659 (2010), 91-95.

[22] G. Szebényi, G. Romhány, B. Vajna, T. Czvikovszky, EB treatment of carbon nanotubereinforced polymer composites, Radiat. Phys. Chem. 81 (2012), 1383-1388.

[22] M. Maciejewska, M. Zaborski, Effect of ionic liquids on the dispersion of zinc oxide and silica nanoparticles, vulcanisation behaviour and properties of NBR composites, Express Polym. Lett. 8 (2014), 932-940. 